\title{
Microplastics - an emerging silent menace to public health
}

\author{
Li-Yin Pang ${ }^{1}$, Shola Sonagara ${ }^{2}$, Oreoluwatomide Oduwole ${ }^{2}$, Christopher \\ Gibbins ${ }^{3}$, Kang-Nee Ting ${ }^{1 *}$
}

${ }^{1}$ School of Pharmacy, University of Nottingham Malaysia, Jalan Broga, 43500 Semenyih, Malaysia. ${ }^{2}$ School of Pharmacy, University of Nottingham, University Park, Nottingham NG7 2RD, United Kingdom.

${ }^{3}$ School of Environmental and Geographical Sciences, University of Nottingham Malaysia, Jalan Broga, 43500 Semenyih, Malaysia.

\section{ABSTRACT}

Over the past few decades, microplastics have become increasingly ubiquitous in the environment and now contaminate the bodies of many living organisms, including humans. Microplastics, as defined here, are plastics within the size range $0.1 \mu \mathrm{m}$ and $5 \mathrm{~mm}$ and are a worrying form of pollution due to public health concerns. This mini-review aims to summarise the route of entry of microplastics into humans and explore the potential detrimental health effects of microplastics. Trophic transfer is an important pathway for microplastic to be transferred across different groups of organisms, with ingestion is regarded as one of the major routes of exposure for humans. Other pathways include inhalation and dermal contact. The health consequences of microplastics manifest because these materials can translocate into the circulatory system and accumulate in the lungs, liver, kidney, and even brain, regardless of the route of entry. Health effects include gastrointestinal disturbances such as inflammation and gut microbiota disruption, respiratory conditions, neurotoxicity and potential cancers. Overall, while it is apparent that microplastics are causing adverse effects on different biological groups and ecosystems, current research is largely focused on marine organisms and aquaculture. Therefore, more studies are needed to investigate specific effects in mammalian cells and tissues, with more long-term epidemiological studies needed on human population considered to be at high-risk due to socioeconomic or other circumstance. Knowledge of the toxicity and long-term health impacts of microplastics is currently limited and requires urgent attention.

* Correspondence

Kang-Nee Ting

School of Pharmacy

University of Nottingham Malaysia Jalan Broga, 43500 Semenyih, Malaysia Kang-Nee.Ting@nottingham.edu.my Tel: +603-8924 8209

Received: 16 September 2020

Revised: 19 November 2020

Accepted: 22 December 2020

Published: 13 January 2021

doi

https://doi.org/10.28916/lsmb.5.1.2021.72
Keywords: Microplastics; plastic additives; pollution; translocation; health

\section{INTRODUCTION}

The use of plastics is increasing exponentially due to their versatility and affordability, with global plastic production totalling almost 360 million tonnes in 2018 (European-Plastics, 2015). While plastics bring many societal benefits by replacing materials used traditionally for fishing, construction and healthcare, as well as in retail and a variety of other industries, a large volume of waste has been produced due to over-usage, single-use, human littering and ineffective waste management. Modelling studies suggest that 4.8 to 12.7 million tonnes of plastic waste are released into the ocean annually, with more plastic pieces than fish estimated to be present in the oceans by 2050 by weight (Ellen MacArthur Foundation, 2016; Jambeck et al., 2015). As a result, plastics have become arguably the most prevalent cause of environmental pollution, attracting much attention headline. 
Plastics are synthetic polymers that include polyethylene, polypropylene, polyester, polyvinyl chloride (PVC) and polytetrafluoroethylene (PTFE). During the manufacture of plastic products, additives such as nonylphenol, bisphenol A (BPA) and pesticides are included to enhance their malleability, flexibility and stability (Hahladakis et al., 2018; Rochman et al., 2015). However, these plastic additives can be gradually released into the environment following the degradation of plastics and exaggerate the impact of plastic pollution. There are two main classes of microplastics, termed primary and secondary. Primary microplastics are intentionally manufactured at a small size, typically less than $5 \mathrm{~mm}$, and they are commonly used in consumer products such as cosmetics, toothpaste and paint (Lehtiniemi et al., 2018). Secondary microplastics, are derived from the degradation and fragmentation of larger plastic items such as water bottles, plastic bags and fishing nets during weathering in the environment (Duis \& Coors, 2016). Other sources of secondary microplastics include abrasion of tyres, synthetic fibres shed from clothes as well as loss of granulates during plastic production (Essel et al., 2015).

Over the past decade, microplastics have been detected ubiquitously in the form of fibres, fragments, pellets and beads (Frias \& Nash, 2019). These are of increasing concern as they are too small for adequate filtration by wastewater treatment plants (WWTPs). Thus, they may escape and contaminate rivers, oceans and the species that occur in these ecosystems (Browne et al., 2011). Cheung \& Fok (2017) estimated that $80 \%$ of microbeads discharged into waters in China stemmed from the inadequate removal in WWTP. This issue is exacerbated in regions without proper WWTP. For example, in Malaysia, approximately 0.199 trillion microplastic particles are emitted annually into the ocean from personal care and cosmetic products in areas without sewage treatment (Praveena et al., 2018).

In general, microplastic pollution is worse in areas where the population size is larger, due to domestic and industrial processes that produce and discharge microplastics. It has become evident that microplastics are toxic to living organisms, so recent research has focused on understanding the risks to human health. This mini-review aims to summarise the transport pathways of microplastics into humans and outline current state of knowledge on the emerging detrimental effects on different species including humans.

\section{ROUTE OF EXPOSURE Ingestion}

In recent years much more information on microplastic ingestion has become available, with this currently regarded as the most important route of entry in humans (Galloway, 2015). An average of 20 microplastic particles (consisting polypropylene and polyethylene) per 10 grams of stool was detected in eight healthy European and Asian volunteers (Schwabl et al., 2019). This finding raises the question of whether all of the ingested microplastics were excreted, and of the extent of microplastic accumulation in their bodies. Despite remaining uncertainties about human contamination and health risks, there is escalating evidence of the accumulation of these non-biodegradable particles in gastrointestinal system, soft tissues and circulatory system of marine organisms. Pathways of microplastics ingestion include misidentification of microplastics for food, passive uptake via accidental consumption, and by trophic transfer (Egbeocha et al., 2018). Evidence of natural trophic transfer of microplastics was first shown in 2013 where an accumulation of polystyrene microspheres was observed in the haemolymph, stomach, hepatopancreas, ovary and gills of crabs fed with food contaminated with these spheres (Farrell \& Nelson, 2013). Hence, it is postulated that microplastics can be transferred to humans via consumption of food species such as mussels, oysters and crabs (Sharma Shivika \& Chatterjee Subhankar, 2017).

Based on the microplastic concentrations measured in bivalves, the annual microplastics intake among the South Korean population was estimated at 212 particles per capita (Cho et al., 2019). This number is slightly lower in the United Kingdom, at 123 particles per capita (Catarino et al., 2018). This differences seems most likely to be related to differences in the dietary pattern between the two countries as average annual per capita seafood consumption in South Korea is nearly 2.8 times higher than in the United Kingdom (Ritchie, 2019). Nevertheless, magnitude of the difference in per capita ingestion suggested by these studies may not reflect overall differences at the population level, as estimates were based solely on microplastic concentration in bivalves.

Interestingly, there are mixed views on whether consumption of microplastics-contaminated seafood is harmful. Differences of opinion stem from arguments that, on the one hand, the gastrointestinal tract of marine organisms (where microplastics mainly accumulate) is considered to rarely be consumed by humans (Wright \& Kelly, 2017) but on the other hand, many marine organisms are eaten whole (e.g. bivalves and crustaceans such as like prawns). Moreover, in Asia, hepatopancreas and gonad of crabs are consumed, and these two internal organs have been reported to accumulate microplastics (McGoran et al., 2020; Shao et al., 2013). It has also been found that the eviscerated flesh of two out of four commonly consumed dried fish species contain higher microplastic quantities than the removed organs (Karami et al., 2017). Hence, evisceration is not likely to be an eliminatory process for microplastics in these seafood. Other than food sources, the use of plastic bottles in daily consumption of water has also been suggested as a significant source of human exposure to microplastics. It is estimated that individuals who only consume water through plastic bottles may ingest 20 times more microplastic particles than those who consumer water directly from taps or other sources (Cox et al., 2019). Section 3 provides further details of translocation of ingested microplastics into the other organs.

\section{Inhalation}

Microplastics are released into the air as a result of numerous anthropogenic processes. For example, the abrasion of materials such as car tyres (made of synthetic rubber), synthetic textiles from the clothing industries as well as flocking processes that involve the use of plastics such as nylon, polyester, and polypropylene (Jin et al., 2019; Tacon \& Metian, 2008), all result in release of microplastics to the environment. As a result of releases, some of which may be directly to air, atmospheric fallout of microplastics is higher in urban areas compared to rural or suburban ones. This suggests that those in densely populated area are at greater risk of exposure to airborne microplastics (Dris et al., Tassin, 2016). Within the Pars Special Energy/Economic Zone (PSEEZ) in Iran, over 1000 microplastic particles were found in every 15 grams of air, compared to 40 particles per 15 grams in residential areas (Abbasi et al., 2019). A recent study indicated that the concentration of microplastics from the air sample in the city of Da Nang, Vietnam, is 9.8 and 1.6 times higher than Japan and Kathmandu, Nepal, respectively (Yukioka et al., 2020). These results illustrate the effect of urbanisation and population density on exposure to microplastic, and suggest inhalation as an important route of entry to humans.

\section{Dermal contact}

Dermal contact is a minor yet important route of entry of microplastics into humans through contaminated water and soil. Although microplastics are generally unlikely to bypass the stratum corneum, those smaller than $25 \mu \mathrm{m}$ are likely to penetrate through human skin pores which have a diameter of 40-80 $\mu \mathrm{m}$ (Enyoh et al., 2019). It is notable that emerging evidence shows that nano-plastics less than $100 \mathrm{~nm}$ are able to penetrate the corneous layer (Lehner et al., 2019). Exposure via dermal contact includes exposure to plastic additives such as BPA and phthalates (Prata et al., 2020). Evaluation of skin surface levels of phthalates through skin wipes on the palm, backof-hand, arm and head from 20 participants showed that the estimated median total daily dermal absorption is $0.48,0.68,0.66(\mu \mathrm{g} / \mathrm{kg})$ for di(isobutyl)phthalate, di(n-butyl)phthalate and $\mathrm{di}(2-$ ethylhexyl)phthalate, respectively (Gong, Zhang, \& Weschler, 2014). This suggests a significant uptake of these phthalates through dermal exposure. 

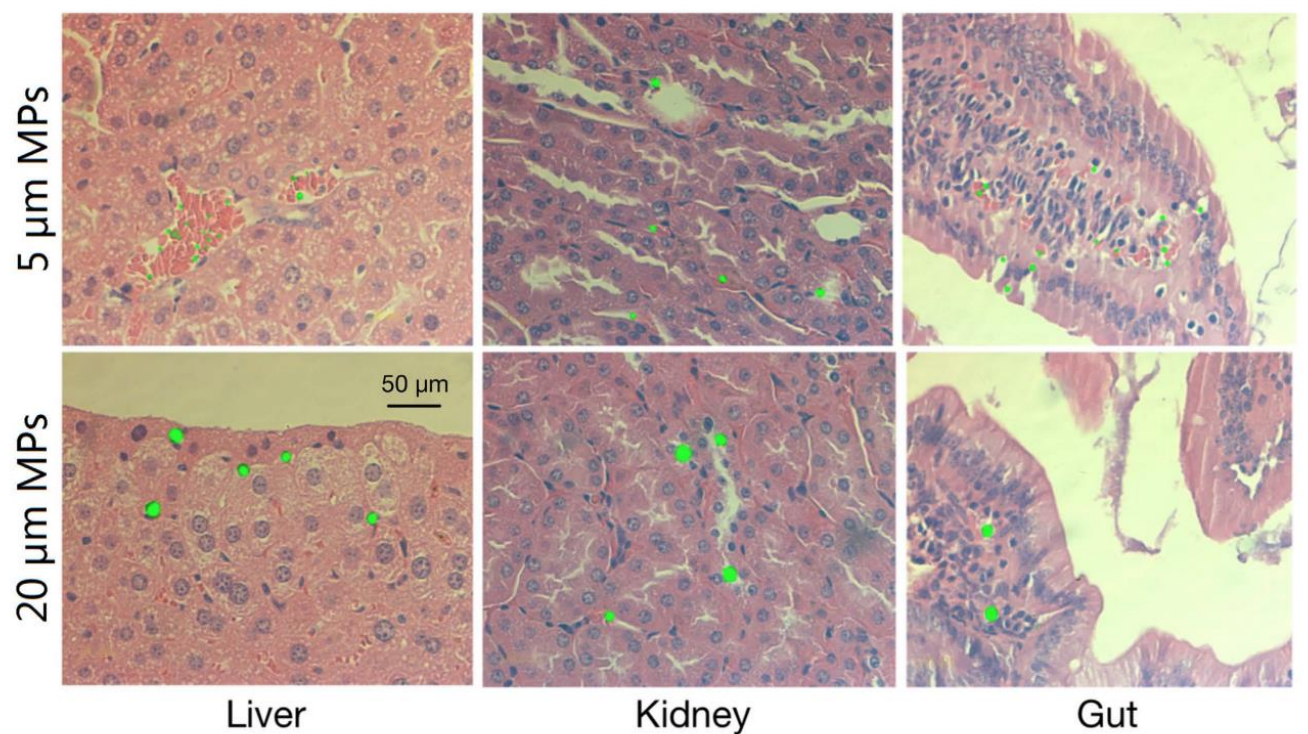

Figure 1: Accumulation of $5 \mu \mathrm{m}$ and $20 \mu \mathrm{m}$ green fluorescent microplastics in the liver, kidney and gut of mice after exposure of $0.01 \mathrm{mg} / \mathrm{day}$ for 28 days by oral gavage. Deng, Y., Zhang, Y., Lemos, B., \& Ren, H. (2017). Tissue accumulation of microplastics in mice and biomarker responses suggest widespread health risks of exposure. Scientific Reports, 7(April), 1-10. https://doi.org/10.1038/srep46687. CC BY 4.0.

\section{TRANSLOCATION OF MICROPLASTICS}

Regardless of the route of entry, microplastics can translocate to the circulatory system, thus broadening exposure in the body and potentially affecting secondary organs and tissues (Wright \& Kelly, 2017). The exact mechanism of microplastic translocation remains unclear. It may happen either via the paracellular pathway through persorption or the transcellular pathway through passive diffusion and endocytosis, or both (De Sales-Ribeiro et al., 2020).

The first piece of evidence detailing the translocation of microplastics was publicised in 2008 when particles were detected in the haemolymph of mussels within 3 days of exposure and persisted in the circulatory system for 48 days (Browne et al., 2008). Since then, many studies have reported the translocation of plastic particles in different species, including bivalves, crabs, crustaceans, sea urchins, fish and mice, all using fluorescent microscopy (Brennecke et al., 2015; De SalesRibeiro et al., 2020; Della Torre et al., 2014; Deng et al., 2017). In the freshwater red tilapia (Oreochronmis niloticus), exposure to polystyrene microplastics for two weeks resulted in the accumulation of microplastics in the order of gut $>$ gills $>$ liver $=$ brain of this fish (Ding et al., 2018). In 2017, Deng et al. made a breakthrough and confirmed the accumulation of microplastics to distant tissues including liver and kidney in mammals (mice) following oral feeding of $0.1 \mathrm{mg}$ green fluorescent polystyrene microplastics with a diameter of $5 \mu \mathrm{m}$ or $20 \mu \mathrm{m}$, for 28 days (Figure 1). Interestingly, the distribution of $20 \mu \mathrm{m}$ microplastics was more consistent in all tissues whereas $5 \mu \mathrm{m}$ microplastics displayed higher accumulation in the gut (Deng et al., 2017). One possible explanation for this is that smaller particles are more easily excreted, reducing the likelihood of accumulation in the body. The damaging health effects of microplastics on physiological systems are discussed in the following sections.

\section{DETRIMENTAL EFFECTS OF MICROPLASTICS ON PHYSIOLOGICAL FUNCTIONS \\ Gastrointestinal disturbances}

Accumulation of microplastics in the digestive tract can result in a blockade and even perforation, thus disrupting the digestion process and leading to reduction of food intake and inhibition of food assimilation (Sharma Shivika \& Chatterjee Subhankar, 2017). Following polystyrene microplastic exposure for 14 days, marine jacopever (Sebastes schlegelii) showed significantly lower sensitivity towards food and prolonged feeding time (Yin et al., 2018). A substantial reduction in growth, protein and lipid contents of this species was also observed by Yin et al., inferring that microplastic exposure diminished the energy reserve and nutritional quality of the fish. Furthermore, ingestion of polystyrene microplastics also caused bile in the gall bladder to turn black and resulted in hepatic hyperaemia, which can be caused by consuming indigestible food (Yin et al., 2018). Other than changes in the liver and gall bladder, morphological change of the intestine has also been reported following microplastics exposure. Exposure of microplastics to European sea bass (Dicentrarchus labrax) for 30 days has resulted in structural alterations of the distal intestine that include widening of the lamina propria, shortening and swelling of the villi as well as increased expression of goblet cells (Pedà et al., 2016). These changes may then disrupt the normal function of the digestive system and cause malnourishment due to insufficient intestinal reabsorption. Additionally, accumulation of microplastics in the intestine and liver has significantly reduced the total cholesterol and triglycerides in rodent models, further emphasising the effect of microplastics on lipid metabolism (Deng et al., 2017). A more recent study confirmed this postulation using an in-vitro simulated human gastrointestinal system, where microplastics including polystyrene, polyethylene terephthalate, polyethylene, PVC, and poly(lactic-co-glycolic acid) significantly inhibited the digestion of lipid (Tan et al., 2020). The authors concluded by detailing two mechanisms that lead to digestion inhibition following exposure to microplastics. Firstly, microplastics may reduce the bioavailability of lipid droplets via formation of large lipid-microplastic aggregates. Secondly, as lipase adsorbed onto the microplastic surface, its activity is reduced due to changes in the secondary structure and disruption of the open conformation of the lid domain (Tan et al., 2020). In general, these studies suggest that ingestion of microplastics may interfere with nutrient absorption in the human body.

Apart from mechanical disruption within the gastrointestinal tract, microplastics in the system may be recognised as foreign bodies and trigger the immune and inflammatory responses. This was observed in blue mussels (Mytilus edulis L.) where formation of granulocytomas (a non-neoplastic inflammatory cellular response) took place after 6 hours of exposure to high concentration of industrial high-density polyethylene (2.5 g HDPE-fluff/L) (Von Moos et al., 2012). As a common indicator of haemocytic response in aquatic animals, the rapid increase of granulocytomas in these blue mussels suggests a considerable cellular host response following microplastics exposure (Von Moos et al., 2012). Inflammation and oxidative stress following exposure to microplastics have been observed in other animal experimental studies, including zebrafish (Jin et al., 2018; Qiao et al., 2019) and mice (Li et al., 2020). Recently, Fackelmann and Sommer (2019) linked dysbiosis to chronic exposure to microplastics. As the immune system maintains the 
homeostasis between host and its gut microbes through the healthy mucosal barrier, microplastic-induced responses such as structural alterations of the intestine are likely to cause microbiome imbalance (Fackelmann \& Sommer, 2019). Although research in this field is still in its infancy, available findings are consistent. These include a significant decrease of gammaproteobacteria in zebrafish and soil oliogochaete (Enchytraeus crypticus) following exposure to polystyrene microplastics (Jin et al., 2018; Zhu et al., 2018). Moreover, daily treatment of $600 \mu \mathrm{g}$ polyethylene microplastics for 5 weeks significantly caused overgrowth of Staphylococcus in the gut of mice (Li et al., 2020). There is no direct evidence yet to suggest the association of microplastic ingestion and dysbiosis in humans, but findings from animal studies, especially mice, clearly provide an indication of the possibility of gut dysbiosis. This is because mice have been shown to be the most useful model for gut microbiota research due to their similarities in physiology and anatomical structure with humans (Nguyen et al., 2015). If ingested microplastics are not excreted, their long-term accumulation may cause dysbiosis and create a vicious cycle in the human gut, leading to further inflammation that may result in inflammatory bowel diseases, irritable bowel syndrome and metabolic disorders (Carding et al., 2015).

\section{Respiratory impairments}

The flock industry represents one of the main contributors to airborne microplastics due to the release of respirable particles during the flocking process (Burkhart et al., 1999). As a result, flocking workers are recruited as the main subjects in many studies. Evidence of the impacts of plastic inhalation on their respiratory health was first acquired in the 1970s, when patients presented with various bronchopulmonary diseases such as asthma and bronchiectasis were found to have been exposed to the inhalation of synthetic fibres at their textile factory workplaces (Cortez Pimentel et al., 1975). Atis et al. (2005) found that among 50 polypropylene flocking workers, $20 \%$ experienced mild pulmonary restriction and $26 \%$ had reduced diffusing capacity. Whilst the difference is not statistically significant, logistic regression analysis showed that the risk of respiratory symptoms is increased by 3.6-fold in polypropylene flocking workers (Atis et al., 2005). In addition, Turcotte et al. (2013) reported that the FEV1/FVC and FEV1 $\%$ predicted values of the flocking workers were significantly lower at follow up compared to their baseline values at the time of screening (a window of 8 to 10 years). The FEV1/FVC and FEV1 \% are standard measurements to examine lung function. In spite of this, the decline in respiratory flow rates in these exposed workers could be a result of smoking as $77 \%$ of them were current or former smokers. Thus, the result may not be conclusive because the extent to which smoking may have contributed to deteriorated lung function is unknown (Turcotte et al., 2013). Although these studies indicate the link between plastic particle inhalation through occupational exposure and respiratory diseases, it is uncertain whether the cause for concern is the material, the processing procedures, the duration of exposure, or a combination of these factors.

The threshold concentration of airborne microplastics in causing respiratory conditions is currently not known. Therefore, the respiratory effects of airborne microplastics might not be limited to industrial workers, as the wider presence of microplastics in the atmosphere may also put the general public at risk. It has also been suggested that most human exposure to airborne microplastics occurs indoors (Catarino et al., 2018). A study of the exposure to indoor airborne microplastics using Breathing Thermal Manikin showed that the total number of microplastics inhaled over 24 hours can reach up to 272 particles (Vianello et al., 2019). Since it is generally accepted that microplastics may deposit in the airways, regardless of their source, the health risk of airborne microplastics is apparent. The risk is even greater in those with existing respiratory conditions such as asthma and chronic obstructive pulmonary disease, since microplastics or other particles may deposit on the respiratory tract more easily due to lower clearance rates (Enyoh et al., 2019). These respiratory impairments induced by microplastics are attributable to the activation of immune and inflammatory response, as deposition of microplastics in the lung parenchyma has been shown to release inflammatory mediators and reactive oxygen species (ROS) (Enyoh et al., 2019). In the human lung epithelial cell line BEAS-2B, 1000 $\mu \mathrm{g} / \mathrm{cm} 2$ of polystyrene microplastics significantly increased the ROS accumulation and reduced the cell viability after 24 hours (Dong et al., 2020). The evidence presented above clearly implies that damages provoked by microplastics to the immune and cellular responses within the lungs leads to long term impairment of the lung function.

\section{Neurotoxicity}

Neurotoxic effects of microplastics have been established in nematodes, bivalves, fish, rodents and several other in-vitro experiments. Exposure of Caenorhabditis elegans to spherical polystyrene microplastics of size 0.1 to $5 \mu \mathrm{m}$ to has caused damage to the cholinergic and GABAergic neurons and resulted in excitatory toxicity on locomotor behaviour (Lei et al., 2018). In clams (Scrobicularia plana), exposure of $1 \mathrm{mg} / \mathrm{L}$ polystyrene microplastics has significantly decreased the acetylcholinesterase activity in the gills within three days (Ribeiro et al., 2017). Other studies have shown that the addition of $10 \mathrm{ng} / \mathrm{L}$ and $100 \mathrm{ng} / \mathrm{L}$ BPA to $1 \mathrm{mg} / \mathrm{L}$ microplastics feed has enhanced the number of neurotransmitters GABA, dopamine and acetylcholine in blood clams (Tegillarca granosa) but reduced the expression of genes encoding the receptors for these neurotransmitters (Tang et al., 2020). All of these findings imply that there are neurotoxic effects of microplastics and BPA in the blood clams. Using a 96-hour laboratory bioassay, 0.26 and 0.69 $\mathrm{mg} / \mathrm{L}$ of microplastics caused $64-76 \%$ inhibition of the brain acetylcholine activity in juvenile European seabass (Dicentrarchus labrax) (Barboza, Vieira, et al., 2018). Exposure of mice to polystyrene microplastics $0.1 \mathrm{mg} /$ day for 28 days resulted in an increase the activity of acetylcholinesterase in the liver and resulted in enhanced threonine, aspartate and taurine levels in serum (Deng et al., 2017). Overall, current studies suggest that microplastic exposure can disrupt the activities of neurotransmitters and the effect is not tissue- and species-specific. It is unknown whether microplastics possess similar neurotoxicity risks to humans, but chronic exposure is likely to induce cell responses and possibly lead to changes to the signalling processes. As discussed above, the ability of these microplastics in evoking inflammatory responses and turning on the oxidative stress reactions will eventually result in neuroinflammation.

\section{Cancers}

The toxicity of vinyl chloride, a monomer used to produce PVC for the use in building, construction, healthcare and automobile industries, has been reported since the 1970s and linked to the development of noncirrhotic portal hypertension and angiosarcoma of the liver in exposed workers (Sherman, 2009). A positive correlation between the duration of exposure and lung cancer risk has been observed, with a two-fold increase in risk for those who have been working in the PVC facility for more than 3.5 years (G. Mastrangelo et al., 2003). Mastrangelo et al. also evaluated the association of exposure to vinyl chloride monomer with hepatocellular carcinoma liver cirrhosis and concluded that exposure is an independent risk factor for hepatocellular carcinoma and liver cirrhosis (Giuseppe Mastrangelo et al., 2004). In addition, Rochman et al. (2013) noticed significant signs of stress in the liver of medaka fish (Oryzias latipes) including glycogen depletion, fatty vacuolation and single-cell necrosis after exposure to virgin polyethylene microplastics and chemically polluted-marine microplastics. It was also noted that one fish from the virgin microplastics-treated group $(n=24 ; n$ : number of fish) showed an eosinophilic focus of cellular alteration, and one fish from the marine microplastics-treated group $(n=19)$ resulted in hepatocellular adenoma which comprised $25 \%$ of the liver. Although the number lesions observed in fish was low, the authors postulated that the formation of pre-neoplastic and neoplastic lesions in these fish is likely related to their exposure to microplastics as no lesions were observed in the control group and formation of spontaneous tumours is very rare in medaka less than one-year-old (Rochman, Hoh, Kurobe, \& Teh, 2013). 


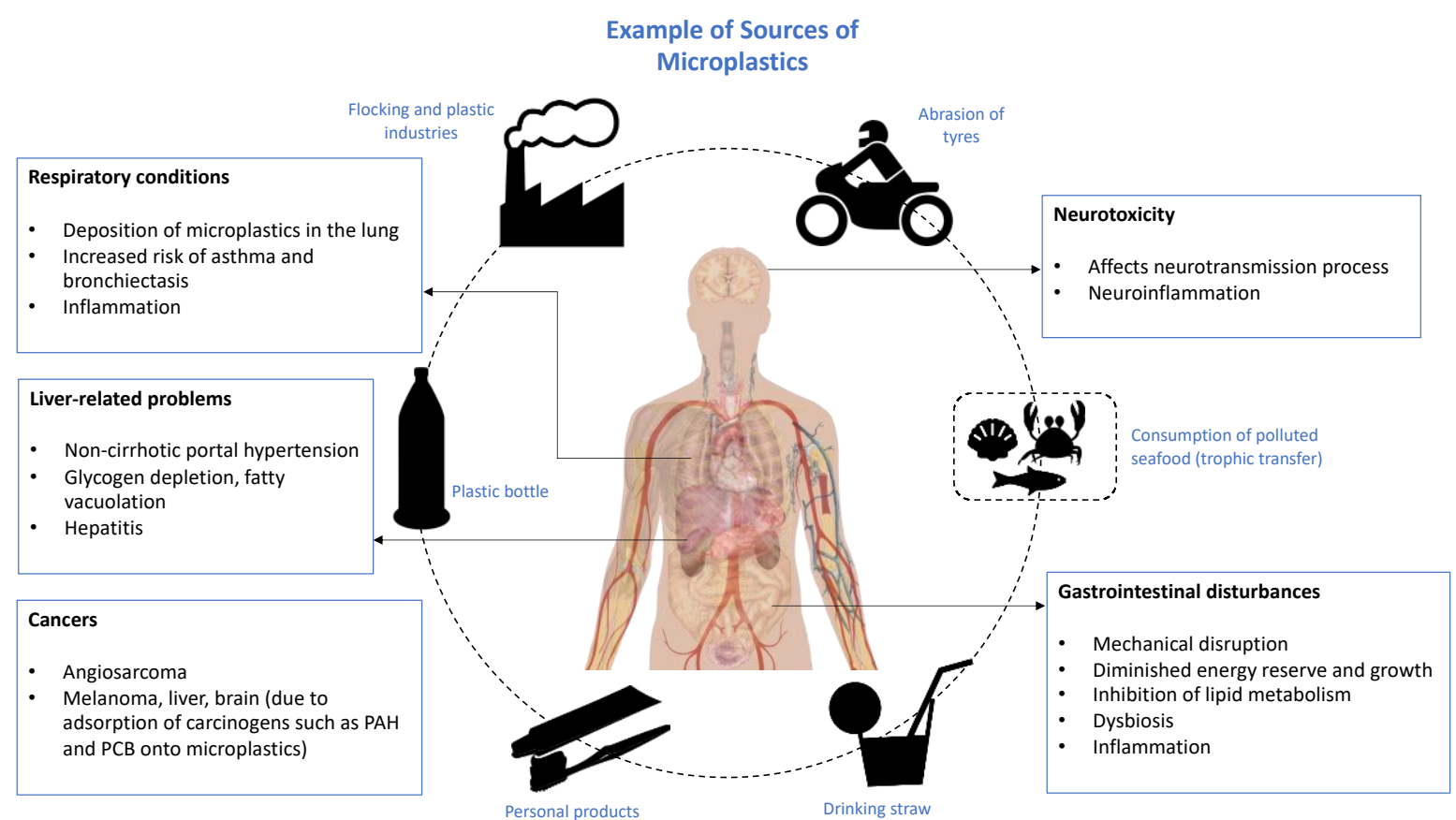

Figure 2: Overview of the sources of microplastics in the environment and their associated health consequences.

Recently, the capability of microplastics to absorb toxins such as polychlorinated biphenyl (PCB) has been highlighted (Verla et al., 2019). This has further heightened the issue as the carcinogenicity of PCB is well established and exposure is associated with increased rates of melanoma, liver cancer, gallbladder cancer, brain cancer (LaubySecretan et al., 2013). Polycyclic aromatic hydrocarbons (PAHs) can also interact and bind with microplastics in water to form PAH-enriched microplastics and changed the degree of toxicity for marine organisms (Koelmans, Bakir, Burton, \& Janssen, 2016). Based on the toxicity equivalency factors (TEFs) for PAHs, the toxicity of PAH-enriched microplastics has been reported to be 1000-times greater than PAHs alone (Sharma et al., 2020). Furthermore, while the acceptable value of incremental lifetime cancer risk (ILCR) is 1x10-6 or lower, it is estimated that ingestion of microplastics and PAHs-enriched microplastics may increase the ILCR to the range of $1 \times 10-5$ to $1 \times 10-4$ (Sharma et al., 2020).

On the whole, exposure to microplastics is associated with farreaching health impacts on living organisms, including humans. These effects are summarised in Figure 2.

\section{CURRENT GAPS IN KNOWLEDGE AND RECOMMENDATIONS FOR FUTURE RESEARCH}

There is a deficit in knowledge of the long-term health effects of microplastics on humans. A critical area to be explored is the threshold concentration of microplastics that poses a health threat, either through ingestion, inhalation or other entering routes. It is also paramount to investigate the effect of chronic sublethal dose exposure to microplastics. Studies involving the concentration of microplastics in the air have been performed in several countries, including Iran, Vietnam and Japan, but due to differences in the environmental sampling and processing methods, it is difficult to compare these studies and apply the findings in other areas or countries. Understanding the sources and types of microplastics in the environment will also enable specific and focused management strategies by the governments and relevant bodies. Moreover, investigations to decipher the common relationships between types of plastic and specific pollutants are needed to provide insights into which pollutants pose the most common and serious threat. Current chemical toxicity testing of microplastics tends to use doses higher than found in the natural environment, often then used to assess effects in less exposed areas. This is ill advised as it ignores the concept of mixed and purely low-dose chemicals (Smith et al., 2018). Nevertheless, it is vital to have more toxicity studies, extending across high to low concentrations, as to date the limited information available has impaired our ability to draw any conclusion about the magnitude of human or ecological risk of observed environmental contamination levels. While much useful work is focussed on marine organisms and in species used in aquaculture, it is important to have other studies of their specific effects in mammalian cells and tissues, including more long-term epidemiology studies on human populations with high exposure risk.

\section{CONCLUSION}

The usage of synthetic polymers continues to increase due to population growth and economic and industrial development. The development of waste treatment and management systems has not kept pace with the rate of plastic production; as a consequence, microplastic pollution has emerged as major environmental issue in the 21st century. Once released into the environment, the fate of microplastics is highly dependent on their sizes and shapes, as well as external environmental factors such as ultraviolet radiation and temperature. Current studies suggest that trophic transfer is the main pathway for the movement of microplastics; following exposure to microplastics through ingestion, inhalation and skin absorption, these particles can be translocated to distant tissues, broadening the potential health impacts. Overall, while it is apparent that microplastics are causing adverse effects on different biological systems, more studies are needed to improve knowledge of transfer pathways, and identify the exact nature and magnitude of risks; such studies are key to provide the foundation for evidence-based strategies designed to reduce human exposure and associated health risks.

\section{DISCLOSURES}

The authors declare no conflicts of interest in this work

\section{ACKNOWLEDGEMENTS}

Li-Yin Pang is a recipient of the Scholarship for PhD in the Faculty of Science and Engineering awarded by University of Nottingham Malaysia. 


\section{REFERENCES}

Abbasi, S., Keshavarzi, B., Moore, F., Turner, A., Kelly, F. J., Dominguez, A. O., \& Jaafarzadeh, N. (2019). Distribution and potential health impacts of microplastics and microrubbers in air and street dusts from Asaluyeh County, Iran. Environmental Pollution, 244, 153-164. https://doi.org/10.1016/j.envpol.2018.10.039

Atis, S., Tutluoglu, B., Levent, E., Ozturk, C., Tunaci, A., Sahin, K., ... Nemery, B. (2005). The respiratory effects of occupational polypropylene flock exposure. European Respiratory Journal, 25(1), 110-117. https://doi.org/10.1183/09031936.04.00138403

Barboza, L. G. A., Dick Vethaak, A., Lavorante, B. R. B. O., Lundebye, A. K., \& Guilhermino, L. (2018). Marine microplastic debris: An emerging issue for food security, food safety and human health. Marine Pollution Bulletin, 133(January), 336-348. https://doi.org/10.1016/j.marpolbul.2018.05.047

Barboza, L. G. A., Vieira, L. R., Branco, V., Figueiredo, N., Carvalho, F., Carvalho, C., \& Guilhermino, L. (2018). Microplastics cause neurotoxicity, oxidative damage and energy-related changes and interact with the bioaccumulation of mercury in the European seabass, Dicentrarchus labrax (Linnaeus, 1758). Aquatic Toxicology, 195, 49-57. https://doi.org/10.1016/i.aquatox.2017.12.008

Brennecke, D., Ferreira, E. C., Costa, T. M. M., Appel, D., da Gama, B. A. P., \& Lenz, M. (2015). Ingested microplastics $(>100 \mu \mathrm{m})$ are translocated to organs of the tropical fiddler crab Uca rapax. Marine Pollution Bulletin, 96(1-2), 491495 .

https://doi.org/10.1016/j.marpolbul.2015.05.001

Browne, M. A., Crump, P., Niven, S. J., Teuten, E., Tonkin, A., Galloway, T., \& Thompson, R. (2011). Accumulation of microplastic on shorelines woldwide: Sources and sinks. Environmental Science and Technology, 45(21), 91759179 https://doi.org/10.1021/es201811s

Browne, M. A., Dissanayake, A., Galloway, T. S., Lowe, D. M., \& Thompson, R. C. (2008). Ingested microscopic plastic translocates to the circulatory system of the mussel, Mytilus edulis (L.). Environmental Science and Technology, 42(13), 5026-5031. https://doi.org/10.1021/es800249a

Burkhart, J., Piacitelli, C., Schwegler-Berry, D., \& Jones, W. (1999). Environmental study of nylon flocking process. Journal of Toxicology and Environmental Health - Part A, 57(1), 1-23. https://doi.org/10.1080/009841099157836

Carding, S., Verbeke, K., Vipond, D. T., Corfe, B. M., \& Owen, L. J. (2015). Dysbiosis of the gut microbiota in disease. Microbial Ecology in Health \& Disease, 26(0).

https://doi.org/10.3402/mehd.v26.26191

Catarino, A. I., Macchia, V., Sanderson, W. G., Thompson, R. C., \& Henry, T. B. (2018). Low levels of microplastics (MP) in wild mussels indicate that MP ingestion by humans is minimal compared to exposure via household fibres fallout during a meal. Environmental Pollution, 237, 675-684. https://doi.org/10.1016/j.envpol.2018.02.069

Cho, Y., Shim, W. J., Jang, M., Han, G. M., \& Hong, S. H. (2019). Abundance and characteristics of microplastics in market bivalves from South Korea. Environmental Pollution, 245, 1107-1116. https://doi.org/10.1016/j.envpol.2018.11.091

Cortez Pimentel, J., Avila, R., \& Galvao Lourenco, A. (1975). Respiratory disease caused by synthetic fibres: a new occupational disease. Thorax, 30(2), 204219. https://doi.org/10.1136/thx.30.2.204

Cox, K. D., Covernton, G. A., Davies, H. L., Dower, J. F., Juanes, F., \& Dudas, S. E. (2019). Human Consumption of Microplastics. Environmental Science and Technology, 53(12), 7068-7074. https://doi.org/10.1021/acs.est.9b01517

De Sales-Ribeiro, C., Brito-Casillas, Y., Fernandez, A., \& Caballero, M. J. (2020). An end to the controversy over the microscopic detection and effects of pristine microplastics in fish organs. Scientific Reports, 10(1). https://doi.org/10.1038/s41598-020-69062-3

Della Torre, C., Bergami, E., Salvati, A., Faleri, C., Cirino, P., Dawson, K. A., \& Corsi, I. (2014). Accumulation and embryotoxicity of polystyrene nanoparticles at early stage of development of sea urchin embryos Paracentrotus lividus. Environmental Science and Technology, 48(20), 12302-12311. https://doi.org/10.1021/es502569w

Deng, Y., Zhang, Y., Lemos, B., \& Ren, H. (2017). Tissue accumulation of microplastics in mice and biomarker responses suggest widespread health risks of exposure. Scientific Reports, 7(April), 1-10. https://doi.org/10.1038/srep46687

Ding, J., Zhang, S., Razanajatovo, R. M., Zou, H., \& Zhu, W. (2018). Accumulation, tissue distribution, and biochemical effects of polystyrene microplastics in the freshwater fish red tilapia (Oreochromis niloticus). Environmental Pollution, 238, 1-9. https://doi.org/10.1016/i.envpol.2018.03.001

Dong, C. Di, Chen, C. W., Chen, Y. C., Chen, H. H., Lee, J. S., \& Lin, C. H. (2020). Polystyrene microplastic particles: In vitro pulmonary toxicity assessment. Journal of Hazardous Materials, 385, 121575. https://doi.org/10.1016/i.jhazmat.2019.121575

Dris, R., Gasperi, J., Saad, M., Mirande, C., \& Tassin, B. (2016). Synthetic fibers in atmospheric fallout: A source of microplastics in the environment? Marine Pollution Bulletin, 104(1-2), 290-293. https://doi.org/10.1016/j.marpolbul.2016.01.006

Duis, K., \& Coors, A. (2016). Microplastics in the aquatic and terrestrial environment: sources (with a specific focus on personal care products), fate and effects. Environmental Sciences Europe, 28(1), 1-25. https://doi.org/10.1186/s12302-015-0069-y

Egbeocha, C. O., Malek, S., Emenike, C. U., \& Milow, P. (2018, September 19). Feasting on microplastics: Ingestion by and effects on marine organisms. Aquatic Biology, Vol. 27, pp. 93-106. https://doi.org/10.3354/ab00701

Ellen MacArthur Foundation. (2016). The New Plastics Economy: Rethinking the future of plastics. Ellen MacArthur Foundation, (January), 120. Retrieved from https://www.ellenmacarthurfoundation.org/publications/the-newplastics-economy-rethinking-the-future-of-plastics

Enyoh, C. E., Verla, A. W., Verla, E. N., Ibe, F. C., \& Amaobi, C. E. (2019). Airborne microplastics: a review study on method for analysis, occurrence, movement and risks. Environmental Monitoring and Assessment, 191(11). https://doi.org/10.1007/s10661-019-7842-0

Essel, R., Ahrens, R. H., Engel, L., \& Carus, M. (2015). Sources of microplastics relevant to marine protection. In Umweltbundesamt. Retrieved from https://www.umweltbundesamt.de/sites/default/files/medien/378/publikatio nen/texte 642015 sources of microplastics relevant to marine protecti on 1.pdf

European-Plastics. (2015). An analysis of European plastics production, demand and waste data. In Plastics - the Facts

Fackelmann, G., \& Sommer, S. (2019). Microplastics and the gut microbiome: How chronically exposed species may suffer from gut dysbiosis. Marine Pollution Bulletin, Vol. 143, pp. 193-203. https://doi.org/10.1016/j.marpolbul.2019.04.030

Farrell, P., \& Nelson, K. (2013). Trophic level transfer of microplastic: Mytilus edulis (L.) to Carcinus maenas (L.). Environmental Pollution, 177, 1-3. https://doi.org/10.1016/j.envpol.2013.01.046

Frias, J. P. G. L., \& Nash, R. (2019). Microplastics: Finding a consensus on the definition. Marine Pollution Bulletin, 138, 145-147. https://doi.org/10.1016/i.marpolbul.2018.11.022

Galloway, T. S. (2015). Micro- and nano-plastics and human health. In Marine Anthropogenic Litter (pp. 343-366). https://doi.org/10.1007/978-3-319-16510-3 13

Gong, M., Zhang, Y., \& Weschler, C. J. (2014). Measurement of phthalates in skin wipes: Estimating exposure from dermal absorption. Environmental Science and Technology, 48(13), 7428-7435. https://doi.org/10.1021/es501700u

Hahladakis, J. N., Velis, C. A., Weber, R., Iacovidou, E., \& Purnell, P. (2018). An overview of chemical additives present in plastics: Migration, release, fate and environmental impact during their use, disposal and recycling. Journal of Hazardous Materials, Vol. 344, pp. 179-199. https://doi.org/10.1016/j.jhazmat.2017.10.014

Jambeck, J. R., Geyer, R., Wilcox, C., Siegler, T. R., Perryman, M., Andrady, A., Law, K. L. (2015). Plastic waste inputs from land into the ocean. Science, 347(6223), 768-771. https://doi.org/10.1126/science.1260352

Jin, Y., Lu, L., Tu, W., Luo, T., \& Fu, Z. (2019). Impacts of polystyrene microplastic on the gut barrier, microbiota and metabolism of mice. Science of the Total Environment, 649, 308-317. https://doi.org/10.1016/j.scitotenv.2018.08.353

Jin, Y., Xia, J., Pan, Z., Yang, J., Wang, W., \& Fu, Z. (2018). Polystyrene microplastics induce microbiota dysbiosis and inflammation in the gut of adult zebrafish. Environmental Pollution, 235, 322-329. https://doi.org/10.1016/j.envpol.2017.12.088

Karami, A., Golieskardi, A., Ho, Y. Bin, Larat, V., \& Salamatinia, B. (2017) Microplastics in eviscerated flesh and excised organs of dried fish. Scientific Reports, 7(1), 1-9. https://doi.org/10.1038/s41598-017-05828-6

Koelmans, A. A., Bakir, A., Burton, G. A., \& Janssen, C. R. (2016). Microplastic as a Vector for Chemicals in the Aquatic Environment: Critical Review and Model-Supported Reinterpretation of Empirical Studies. Environmental Science and Technology, Vol. 50, pp. 3315-3326. https://doi.org/10.1021/acs.est.5b06069 
Lauby-Secretan, B., Loomis, D., Grosse, Y., El Ghissassi, F., Bouvard, V., Benbrahim-Tallaa, L., ... Straif, K. (2013). Carcinogenicity of polychlorinated biphenyls and polybrominated biphenyls. The Lancet Oncology, 14(4), 287288. https://doi.org/10.1016/S1470-2045(13)70104-9

Lehner, R., Weder, C., Petri-Fink, A., \& Rothen-Rutishauser, B. (2019). Emergence of Nanoplastic in the Environment and Possible Impact on Human Health. Environmental Science and Technology, 53(4), 1748-1765. https://doi.org/10.1021/acs.est.8b05512

Lehtiniemi, M., Hartikainen, S., Näkki, P., Engström-Öst, J., Koistinen, A., \& Setälä, O. (2018). Size matters more than shape: Ingestion of primary and secondary microplastics by small predators. Food Webs, 17. https://doi.org/10.1016/j.fooweb.2018.e00097

Lei, L., Liu, M., Song, Y., Lu, S., Hu, J., Cao, C., ... He, D. (2018). Polystyrene (nano)microplastics cause size-dependent neurotoxicity, oxidative damage and other adverse effects in Caenorhabditis elegans. Environmental Science: Nano, 5(8), 2009-2020. https://doi.org/10.1039/C8EN00412A

Li, B., Ding, Y., Cheng, X., Sheng, D., Xu, Z., Rong, Q., ... Zhang, Y. (2020). Polyethylene microplastics affect the distribution of gut microbiota and inflammation development in mice. Chemosphere, 244(5), 690-697. https://doi.org/10.1016/j.chemosphere.2019.125492

Mastrangelo, G., Fedeli, U., Fadda, E., Milan, G., Turato, A., \& Pavanello, S. (2003). Lung cancer risk in workers exposed to poly(vinyl chloride) dust: A nested case-referent study. Occupational and Environmental Medicine, 60(6), 423428 . https://doi.org/10.1136/oem.60.6.423

Mastrangelo, Giuseppe, Fedeli, U., Fadda, E., Valentini, F., Agnesi, R., Magarotto, G., ... Martines, D. (2004). Increased risk of hepatocellular carcinoma and liver cirrhosis in vinyl chloride workers: Synergistic effect of occupational exposure with alcohol intake. Environmental Health Perspectives, 112(11), 1188-1192.

https://doi.org/10.1289/ehp.6972

McGoran, A. R., Clark, P. F., Smith, B. D., \& Morritt, D. (2020). High prevalence of plastic ingestion by Eriocheir sinensis and Carcinus maenas (Crustacea: Decapoda: Brachyura) in the Thames Estuary. Environmental Pollution, 265. https://doi.org/10.1016/i.envpol.2020.114972

Nguyen, T. L. A., Vieira-Silva, S., Liston, A., \& Raes, J. (2015). How informative is the mouse for human gut microbiota research? DMM Disease Models and Mechanisms, 8(1), 1-16. https://doi.org/10.1242/dmm.017400

Pedà, C., Caccamo, L., Fossi, M. C., Gai, F., Andaloro, F., Genovese, L., ... Maricchiolo, G. (2016). Intestinal alterations in European sea bass Dicentrarchus labrax (Linnaeus, 1758) exposed to microplastics: Preliminary results. Environmental Pollution, 212, 251-256. https://doi.org/10.1016/i.envpol.2016.01.083

Prata, J. C., da Costa, J. P., Lopes, I., Duarte, A. C., \& Rocha-Santos, T. (2020). Environmental exposure to microplastics: An overview on possible human health effects. Science of the Total Environment, 702. https://doi.org/10.1016/j.scitotenv.2019.134455

Praveena, S. M., Shaifuddin, S. N. M., \& Akizuki, S. (2018). Exploration of microplastics from personal care and cosmetic products and its estimated emissions to marine environment: An evidence from Malaysia. Marine Pollution Bulletin, 136, 135-140. https://doi.org/10.1016/i.marpolbul.2018.09.012

Qiao, R., Sheng, C., Lu, Y., Zhang, Y., Ren, H., \& Lemos, B. (2019). Microplastics induce intestinal inflammation, oxidative stress, and disorders of metabolome and microbiome in zebrafish. Science of the Total Environment, 662, 246-253. https://doi.org/10.1016/j.scitotenv.2019.01.245

Ribeiro, F., Garcia, A. R., Pereira, B. P., Fonseca, M., Mestre, N. C., Fonseca, T. G., ... Bebianno, M. J. (2017). Microplastics effects in Scrobicularia plana. Marine Pollution Bulletin, 122(1-2), 379-391. https://doi.org/10.1016/j.marpolbul.2017.06.078

Ritchie, H. (2019). Seafood Production. Retrieved November 9, 2020, from OurWorldInData.org website: $\underline{\text { https://ourworldindata.org/seafood- }}$ production

Rochman, C. M., Hoh, E., Kurobe, T., \& Teh, S. J. (2013). Ingested plastic transfers hazardous chemicals to fish and induces hepatic stress. Scientific Reports, 3 . https://doi.org/10.1038/srep03263

Rochman, C. M., Kross, S. M., Armstrong, J. B., Bogan, M. T., Darling, E. S., Green, S. J., ... Veríssimo, D. (2015). Scientific Evidence Supports a Ban on Microbeads. Environmental Science and Technology, 49(18), 10759-10761. https://doi.org/10.1021/acs.est.5b03909

Schwabl, P., Koppel, S., Konigshofer, P., Bucsics, T., Trauner, M., Reiberger, T., \& Liebmann, B. (2019). Detection of various microplastics in human stool: A prospective case series. Annals of Internal Medicine, 171(7), 453-457. https://doi.org/10.7326/M19-0618
Shao, L., Wang, C., He, J., Wu, X., \& Cheng, Y. (2013). Hepatopancreas and gonad quality of chinese mitten crabs fattened with natural and formulated diets. Journal of Food Quality, 36(3), 217-227. https://doi.org/10.1111/jfq.12030

Sharma, M. D., Elanjickal, A. I., Mankar, J. S., \& Krupadam, R. J. (2020). Assessment of cancer risk of microplastics enriched with polycyclic aromatic hydrocarbons. Journal of Hazardous Materials, 398. https://doi.org/10.1016/j.jhazmat.2020.122994

Sharma Shivika, \& Chatterjee Subhankar. (2017). Microplastic pollution, a threat to marine ecosystem and human health: a short review. Environmental Science and Pollution Research, 24(27), 21530-21547. https://doi.org/10.1007/s11356-017-9910-8

Sherman, M. (2009). Vinyl chloride and the liver. Journal of Hepatology, Vol. 51, pp. 1074-1081. https://doi.org/10.1016/j.jhep.2009.09.012

Smith, M., Love, D. C., Rochman, C. M., \& Neff, R. A. (2018, September 1). Microplastics in Seafood and the Implications for Human Health. Current Environmental Health Reports, Vol. 5, pp. 375-386. https://doi.org/10.1007/s40572-018-0206-Z

Tacon, A. G. J., \& Metian, M. (2008). Global overview on the use of fish meal and fish oil in industrially compounded aquafeeds: Trends and future prospects. Aquaculture, 285(1-4), 146-158 https://doi.org/10.1016/j.aquaculture.2008.08.015

Tan, H., Yue, T., Xu, Y., Zhao, J., \& Xing, B. (2020). Microplastics Reduce Lipid Digestion in Simulated Human Gastrointestinal System. Environmental Science \& Technology, 54(19), 12285-12294. https://doi.org/10.1021/acs.est.0c02608

Tang, Y., Zhou, W., Sun, S., Du, X., Han, Y., Shi, W., \& Liu, G. (2020). Immunotoxicity and neurotoxicity of bisphenol A and microplastics alone or in combination to a bivalve species, Tegillarca granosa. Environmental Pollution, 265 https://doi.org/10.1016/i.envpol.2020.115115

Turcotte, S. E., Chee, A., Walsh, R., Grant, F. C., Liss, G. M., Boag, A., ... Lougheed, M. D. (2013). Flock worker's lung disease: Natural history of cases and exposed workers in Kingston, Ontario. Chest, 143(6), 1642-1648. https://doi.org/10.1378/chest.12-0920

Verla, A. W., Enyoh, C. E., Verla, E. N., \& Nwarnorh, K. O. (2019). Microplastictoxic chemical interaction: a review study on quantified levels, mechanism and implication. SN Applied Sciences, 1(11). https://doi.org/10.1007/s42452-019-1352-0

Vianello, A., Jensen, R. L., Liu, L., \& Vollertsen, J. (2019). Simulating human exposure to indoor airborne microplastics using a Breathing Thermal Manikin. Scientific Reports, 9(1), 1-11. https://doi.org/10.1038/s41598-019-45054-w

Von Moos, N., Burkhardt-Holm, P., \& Köhler, A. (2012). Uptake and effects of microplastics on cells and tissue of the blue mussel Mytilus edulis L. after an experimental exposure. Environmental Science and Technology, 46(20), 11327-11335. https://doi.org/10.1021/es302332w

Wright, S. L., \& Kelly, F. J. (2017). Plastic and Human Health: A Micro Issue? Environmental Science and Technology, 51(12), 6634-6647. https://doi.org/10.1021/acs.est.7b00423

Yin, L., Chen, B., Xia, B., Shi, X., \& Qu, K. (2018). Polystyrene microplastics alter the behavior, energy reserve and nutritional composition of marine jacopever (Sebastes schlegelii). Journal of Hazardous Materials, 360, 97-105. https://doi.org/10.1016/j.jhazmat.2018.07.110

Yukioka, S., Tanaka, S., Nabetani, Y., Suzuki, Y., Ushijima, T., Fujii, S., ... Singh, S. (2020). Occurrence and characteristics of microplastics in surface road dust in Kusatsu (Japan), Da Nang (Vietnam), and Kathmandu (Nepal). Environmental Pollution, 256 https://doi.org/10.1016/j.envpol.2019.113447

Zhu, B. K., Fang, Y. M., Zhu, D., Christie, P., Ke, X., \& Zhu, Y. G. (2018). Exposure to nanoplastics disturbs the gut microbiome in the soil oligochaete Enchytraeus crypticus. Environmental Pollution, 239, 408-415. https://doi.org/10.1016/j.envpol.2018.04.017

Citation:

Pang, L.-Y., Sonagara, S., Oduwole, O., Gibbins, C., \& Kang Nee, T. (2021). Microplastics - an emerging silent menace to public health. Life Sciences, Medicine and Biomedicine, 5(1). https://doi.org/10.28916/lsmb.5.1.2021.72 
Copyright (c) 2021 by the Author(s). Life Sciences, Medicine and Biomedicine (ISSN: 2600-7207) Published by Biome Journals - Biome Scientia Sdn Bhd. Attribution 4.0 International (CC BY 4.0). This open access article is distributed based on the terms and conditions of the Creative Commons Attribution license https://creativecommons.org/licenses/by/4.0/

Life Sciences, Medicine and Biomedicine ISSN: 2600-7207 